\title{
Large Interactive Media Display and Its Influence on Transformation Urban Spaces from Neglecting to Action: The Case of Al-Thaqafa Street in Amman City
}

\author{
Wael Al-Azhari, Lana Haddad, Muhammad Al Absi \\ Department of Architecture, The University of Jordan, Amman, Jordan \\ Email: w.alazhari@ju.edu.jo
}

Received 24 June 2014; revised 23 July 2014; accepted 15 August 2014

Copyright (C) 2014 by authors and Scientific Research Publishing Inc.

This work is licensed under the Creative Commons Attribution International License (CC BY). http://creativecommons.org/licenses/by/4.0/

(c) (i) Open Access

\begin{abstract}
In $21^{\text {st }}$ century, media become the most important factor affecting the development of urban cities, including public places. As a result of the digital revolution, re-imaging and re-linkage public places by media are essential to create more interactions between public spaces and users, interaction media display, and urban screens, one of the most important defined media. This interaction can transform the urban space from being neglected to be more interactive space with users, specially the pedestrians. This paper aims to identify the effects of these new digital factors to transform public spaces, and the influences of large media display on the interaction between urban spaces and pedestrians. The paper focuses on Al-Thaqafa Street as one of the neglected spaces in Amman city, and attempts to analyse this street, explains its problems, and studies the influence of these new digital factors on its transformation, to be more active and vital by pedestrians.
\end{abstract}

\section{Keywords}

Large Media Display, Neglected Spaces, Transform Urban Spaces, Active Spaces, Pedestrians

\section{Introduction}

Large media display (LMD) is contemporary product of Mediatecture which integrated media in architecture; it is a form of communication and interaction in urban spaces. Also, it is forms of the interface between the virtual and real worlds. Media facade contacts with the public audience within public spaces by optical methods, represents a new entity that sets standards, and gives identity and cultural value of public space [1]. Urban screens 
and media facade comprise a category of urban computing concerned with the integration of displays into the built environment, including buildings and street furniture. LMD represents a new kind of ubiquitous interface in place which applies on all static components of the interface, to give the place a high dynamic situation; it presents information in a highly visual and interactive way [2]. Media facade describes the idea of designing or modifying the architecture of buildings, using their surface as giant public screens of buildings, using their surface as giant public screens. LMD connects the physical components and people in the same urban space, which play as an interaction role, which contributes to the transfer public spaces from neglect to action.

\section{Visual Preceptions in Urban Spaces}

The main content of any urban space should develop during years to conduct the growth of space form. In $21^{\text {st }}$ century the development of architecture path is heading towards digital technology, Meda (2013) in Bettery Magazine stated: "your experience in your city, in your home or your car or your office, is often a result of some technology that has become an innate part of daily urban life... but it is made special and unique by design” [3], as a result we should try to identify and extract this idea to reuse and applying it for the public interest.

Urban spaces were determined as three components according to Norberg-Schulz (1967), it is a concepts of Jord, Himmel, and Synsrand; the Earth, sky, and optical array [4]. In other words, the features of any place identifying by what we walk on, above and around us, now a day some changes accrued on the visual character of these features, especially the surrounding, due to its effect on the identity of place in many disciplines such as culture, educational investment and social interaction.

Visual characters offer images which changes according to need, users perceptions and time, as Rapoport and Kantor (1967) mentioned "The two most important formal factors affecting judgment are order and visual interest that tends toward ambiguity and complexity", therefore the perception of the viewer changing per-unit according to scenes or physical environment, as "slow-moving pedestrians require a high level of complexity to hold their interest” [5].

These images or scenes can be memorable according to users' perception and the strongest effect of feature elements of the space, in order to Ewing and Bartholomew (2013), image-ability is about the space quality which makes it memorable, distinguish , recognizable, even they used the term of complexity to explains the diversity of images as we mentioned before [6].

The complexity of any urban space is a result of many aspects refers to color, texture, size, shape, style, ornament, distance, motion and urban features. These aspects are changing the space to be liveable, dynamic and consider as non-classical boundary, so if the complexity is high then the perception increase, especially when the senses interpreting and sensing the environment, that's provides a suitable and liveable environment [7]. So, the spaces considered to be more liveable and safe by the pedestrians presence so we must be sure that any chosen place should be familiar and simply interact with users, the place become more friendlier, if it became more visitable [8].

According to the previous point, a new term has been risen by Woolley and Rose (2004), which is Home Zone; "it is demonstrating the benefits of redesigning streets for shared use by residents and pedestrians not just for cars" [9].

\subsection{Interaction in Urban Spaces}

Interactivity and digitally is a new and main criterion in architectural design, including urban spaces design, according to Moggridge (2007) "the design of everything that is both digital and interactive" [10]. Interactive architecture is a new trend, will develop in near future, that architecture will not be static as before, it is a "revolutionizing" and "reinventing" the relationships between users and architecture components, in all scales: work, home, and cities [11]. So, Architecture of intelligence is the architecture of connectivity.

In urban spaces, Interactivity is an opportunity for users to shared experience and input in the community; it is a chance to express themselves [12]. Interactivity makes reaction between users and urban spaces and makes users to walk, stand, sit, see, hear and talk. In another words, interactivity is how users invest the time, skill, knowledge, and imagination in environments [13]. These reactions print indelible image in memory with multisensory experience with the place. Good urban spaces can and should, therefore, perform a multitude of important functions for as wide a range of the community as possible [14].

Many researcher deals with interactions and activities in urban spaces in several principles, types and aspects, 
interaction has two types: direct and indirect interaction. Amin (2002) put three principles of designing urban spaces quality, one of them is the wider relationship between design, setting in place and time [15]. The types of activities in public spaces, which Gehl (1971) talks about in life between buildings, are necessary, optional and social activities, these three types combine to create meaningful and attractive space, which can use by individual user, groups and crowds [16]. Brignull and Rogers (2003) focus on three interactive activities in public spaces and set three types; the first is peripheral awareness activities: typically eating, drinking and socializing, the second is focal awareness activities, people in these activity spaces are engaging in socializing activities associated with the display, and the final is direct interaction activities, all these activities may be have direct or indirect interaction [17], in understanding the Dynamics of Engaging Interaction Public Spaces, that users formed by four elements should be in interaction design: cultural practices, physical conditions, the content of the installations, and social practices [13], then the positive user experience has created, that become an important success factor of interactive systems.

In interaction design, there are three ways to set interaction: technology, behaviorist, social Interaction, in this views the design make technology, particularly digital technology, useful, usable, and pleasurable to use, and how technology product behave and make connection between people [18]. Human Computer Interaction (HCI) grew to represent the interaction between people and technology, HCI shift people from seeing machinery to use it, that make our interaction success [19], and users experience will improved in public space with technology components, Moggridge (2007) says: "Designers of digital technology products no longer regard their job as designing a physical object ‘beautiful or utilitarian' but as designing our interactions with it” [10].

The product of new media and urban computing were developed rapidly to make new attraction between people and space, Media which is a part of technology become the important factor influences in urban spaces quality [20], the most type of media interacts with people in urban space is media display and media facade, it behave like a video-sculpture or a television of an urban measure, and have an awareness role that architecture is always as message and the media facade emits these messages [1], interaction media display aims to connect people locally and remotely, it become a novel communication media, such as public displays can act as "community glue" that help to end social separation. Interaction media display categorizes into two groups: "public displays in combination with mobile devices" and "standalone public displays" [21].

Interaction by LMD have many principles to set in urban space, Vogel and Balakrishnan (2005) sum a list of principles for how public display make an interaction in urban space, comprehension, notifications, short-duration fluid interaction, immediate usability, shared use, combining public and personal Information, privacy [22]. These visual perception and interaction theories classified the LMD as a proper solution to transform neglected urban spaces.

\subsection{Transformation Urban Space with LMD}

Any urban spaces defined by multi variables such as socioeconomically environmental, political, human behavior and surroundings precedents, the most important variable is human behaviour, despite of, the variant properties that must related to a complementary relationship, as Jacobs (1993) said "Urban spaces must respond to their surrounding context and create a mutual relationship between the areas. The spaces should complement one another's strengths and minimize their weaknesses" [23].

These variables and the connection in between, shows a huge transformation of any space to convert it into a proper place, therefore the transformation of architecture and urban spaces, as we see it's the changing in current appearance which influence by human behavior and environmental factors, leading to transform it into liveable and more interactive place.

As we stated previously, human behaviour is one of the most important aspect due to its influence, Vogel and Balakrishnan (2005) have points out, "On the other hand, multiple users create a significant amount of social content, so even a simple design can quickly become lively and complex when many people are interacting” [22].

In order to, behind human behavior, any new form and other Externalities, they could change our place adaptively with surroundings [24].

The adaptation of the surrounding effected by the performance of how users and things act with these changes transformation, Counsell and Wolf (2001) "translating real bodies, words, and movements into the objects of another, hypothetical world" [25]. Also Lefebvre (2008) "The empirically demonstrable everyday transforma- 
tion of social space into physical or geographical space produces the symbolic meaning of a spatial representation of social reality" [26].

Naturally these transformations will effect user's perceptions and how they dealing with it, "From the user perspective, interaction occurs in phases: passing by, viewing and reacting, subtle interaction, direct interaction, multiple interactions, and follow-up actions" [27].

Interactions are varied, but our concern is about the new display technology, any shape of surface, will be a candidate for being a part of the real world instead of being virtual", "Ubiquitous displays offer a way to transform an urban space into a sociable place. A place is a space with meaning: spaces are merely constructed areas" [28].

Many potential indicators show the relationship between urban screen and users of urban spaces and how urban screens transform urban spaces, therefore it will be social spaces, that will include many cultural practices, and the important events will become more present in people's memory. Urban screens will set the creativity in urban space, screens can creative interaction activity not only by stakeholders, but also users can participate to present shows that they created, in addition to the many awareness campaigns that can be presented [29].

By all these changes which aspiring to create new spaces, a new definition appears, has stated "Let everyday life become a work of art! Let every technical means be employed for the transformation of everyday life" [26].

\section{The Methodological Basis}

The concept of cultural streets known widely through the world, ancient tribes had been developed the spaces through the years as Lawson (2001) stated "when they became aware of it" till date [30], such places were designed to multipurpose function as acting, debating with others and casting a poems etc. Currently it became more hyper and liveable space in order to introduce different kinds of art which integrated with other kind of technology, because it's all about the importance of interaction within specific place which emphasizing on the importance of visual perception in developing the spaces as Perovic and Folic (2012) proposed that "theories of visual perception: indicate the need for multiple approaches to visual perception and its importance for the development of quality urban spaces” [31].

\section{Methodology}

The research was carried in Amman city, the capital of Jordan with a population around three million as 2013 statistical survey stated, at Al-Thaqafa Street, Shmaisani. This street is a commercial street, was built in 2001 by architect Tom Postma, it was designed to announce Amman city as the Arab cultural capital, and it is all about participation of local artists and authors in such a festivals and galleries. Even it has got a book shop, platform for poetry evenings, a place for cultural exchange, gathering area and a place for honoured the creative and artistic symbols of Jordanian figures. The street is about 315 meter length and 12 to 16 meter width. The public space hosts numbers of banks, commercial buildings and restaurants beside the most important spaces the intermediate zone (gathering areas, the gallery and the sculpture zone) (Figure 1). To gain the maximum benefit of this part, we started with data collection about the same subject to present the advanced technology in interaction media display that we aim to apply, secondly, presented the result of the questionnaire. By observation, visual-interactive analyze has done of the street to set position of embodied LMD, this analysis identified some factors that affect of alternative suggestions.

\section{Case Studies}

The case studies that are presented have an advanced interaction media display, in addition to the clear interest outputs, content and how people interact with them. These cases show how the contribution of external stakeholders from the public and the private sector, the diversity of LMD and the different technology used in, all off these cases facade are formed without media, later transforming into media display facade, we choose four cases with four interaction stages; users expressed himself, guided interaction, direct interaction, interaction with advertisement.

\subsection{Spacing, Stubengasse Münster, Germany}

Spacing project (Spacing “Abstraction of Movement \& Dimension” 2010), the main purpose was to create artifi- 


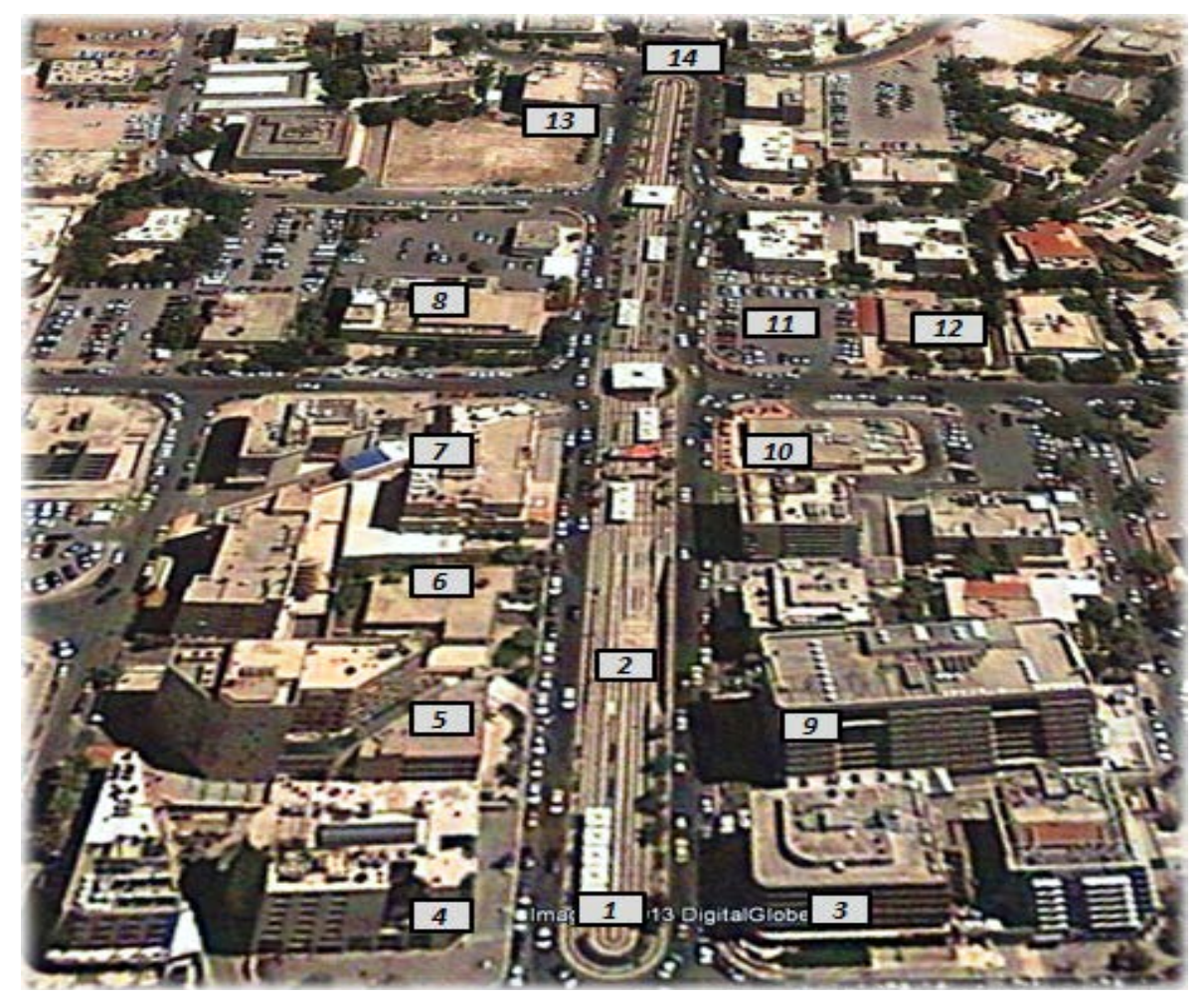

Figure 1. (1) Gathering Spaces; (2) Sunken Gallery; (3) Nokia Center; (4) Oracle Tower; (5) Arab Jordan Investment Bank; (6) Commercial Building; (7) Commercial Building; (8) Commercial Building; (9) Islamic Bank Building; (10) Restaurant; (11) Parking; (12) Houses; (13) Commercial Building; (14) HSBC Bank (The Authors, 2014).

cial phenomena in urban space. With $70 \times 20 \mathrm{~m}$ of media display, dance, graphics, sound \& architecture have been played (Figure 2). The concept created by Till Botterweck, spacing is a principle that translated into specific aspects of the folk dance by 3D-video-mapping, The Direct projection on the facade is forced audience to move to the right and left during the presentation, this project put facade in narrative within urban space [32].

\subsection{Body Movies, Rotterdam, the Netherlands}

Body Movies (2001) by Rafael Lozano-Hemmer, used over than one thousand pictures on the streets of Rotterdam, Madrid, Mexico and Montreal-taken by robotically controlled projectors located around the square (Figure 3). The pictures only appeared As soon as someone walked on the square carpet, his or her shadow was projected on the facade. People embody the narrative representation on the facade in 1200 square meters of projections, but individual participation is a few [33].

\subsection{Climate on the Wall, Aarhus, Denmark}

During the climate exhibition (2009), the people in Aarhus could engage with the climate improvements by using Climate on the Wall, which done by sentences Center for Digital Urban Living, used the facade of Ridehuset (historical building), it is display by means of projection technology, (Figure 4). On the facade, many sentences relating to carbon emissions and climate issues floated around above the heads of passers-by as bubbles, if a person stopped, the sentences above the person would grow and turn into a speech bubble. In this way, people were able to create and manipulate sentences relating to climate change and carbon emission [34].

\subsection{Authority Bus Terminal, New York, United States}

The Port Authority Bus Terminal is the biggest bus station in the United States and busiest in the world, more than 200,000 people passing through the terminal daily. This terminal is very dynamics, the media screens must 


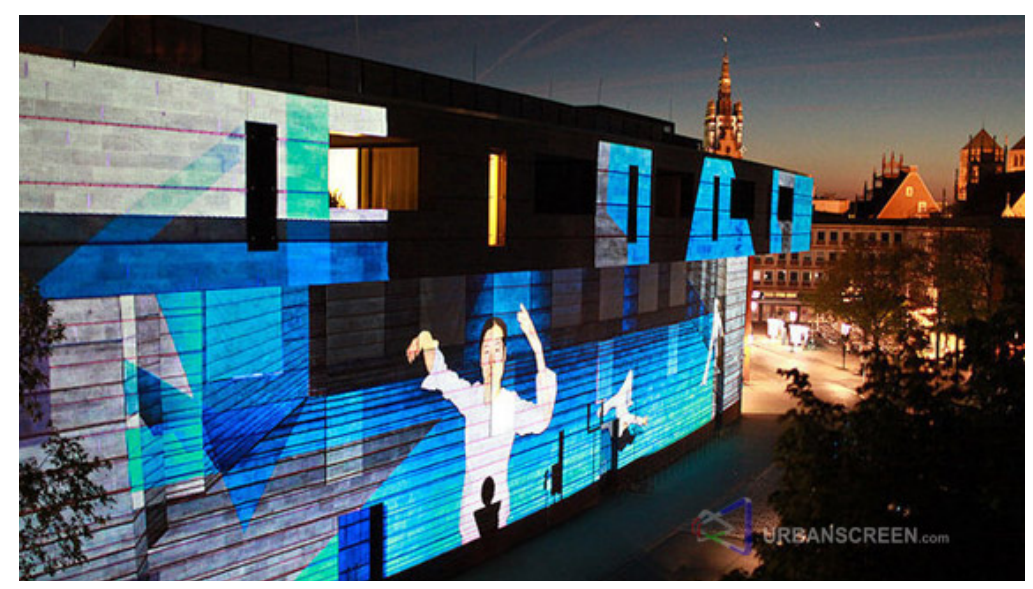

Figure 2. Spacing creates artificial phenomena in urban space large architecture-projection in $70 \times 20 \mathrm{~m}$, Stubengasse Münster, Germany.

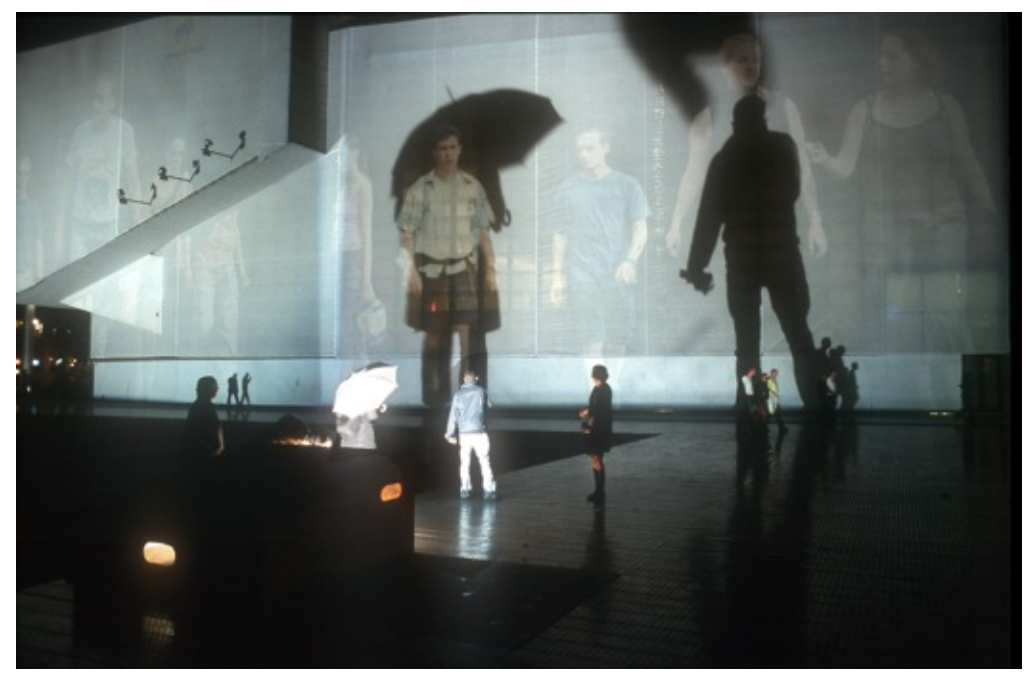

Figure 3. Body movies by Rafael Lozano-Hemmer, Rotterdam, Netherlands.

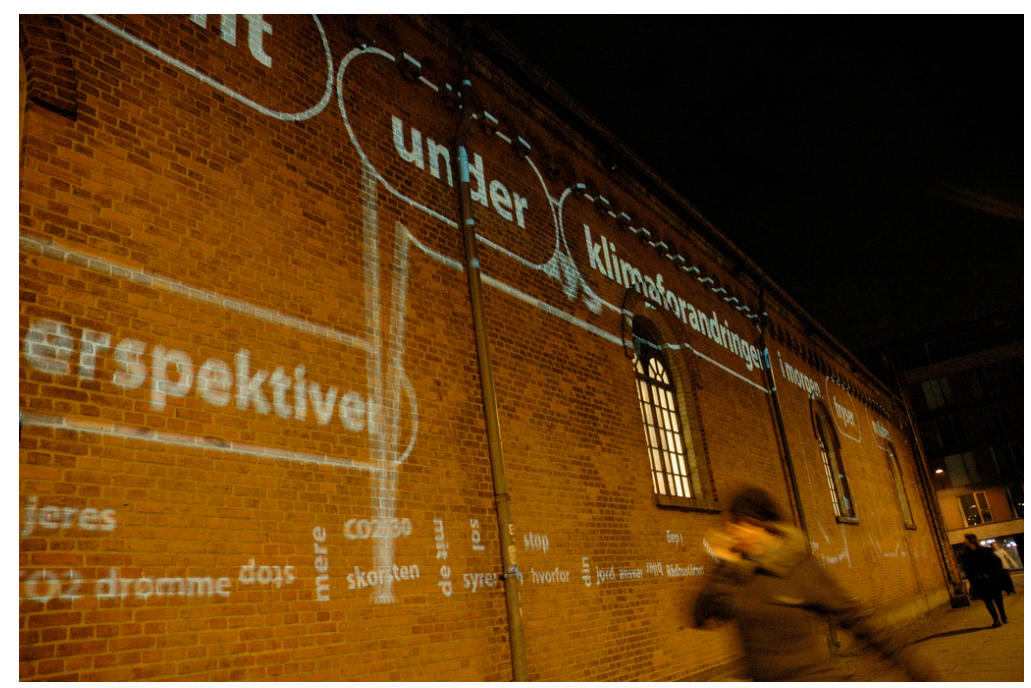

Figure 4. Climate on the wall by sentences center for Digital Urban Living, Aarhus, Denmark (Fritsch and Brynsko, 2009). 
characterized by the rapid display, it only displays advertisements and beautiful images interact with the whole facade and that does not disrupt the movement and keeping a smooth people flow. The technology used; Media mesh, integrated LED profiles. This technology provides images and full visibility with the daylight (Figure 5) [35].

\section{The Questionnaire}

According of our methodology, the authors had to stimulate user's opinion by a questionnaire, because they are prefer to respond questions are relevant to them [36]. Close ended questionnaire, test many concepts raised in this paper. The purpose sample is taken randomly from visitors and investors of the street. In order to conduct a questionnaire; Number of the sample is 30 people with ranging age from 15 to 55 years, and $83 \%$ from the sample are permanent visitors (Table 1 ).

Questionnaire include two parts of questions, the first part aims to find out that if the street was neglected, also to identify its causes, this part is support the problem that the paper assumed by observation. The second part of questions checks if the large media display is a good solution to the problem of neglect statues. Some followed questions are used to specify the neglected causes in the street, and if people want to be engaging to the large media display.

The results show that, the majority of the samples recognized the importance of the street; these results are indicators to start solving the street problems. One of these problems is the gap between the street name and the currently activities. On the other hand, the results shows that; the street is already neglected and we have to reform the space properly, leading to strength connection between the name and the street importance (Table 1).

In Table 2 the followed questions tried to specify the reasons of why the street is neglected? Because the lack of audio and visual effect in the street, even the lake of vital facilities. According to people's choices, other problems are also having a great influence on Al-Thaqafa Street; the lack of interactive activities and the low cultural level to the current visitors. Finally, the most contents that people like to display on the large media are sports and natural séance (Table 2).

\section{Discussion}

According to the observation, the pedestrians were distributed in two spaces according to the street function which split into sitting area, sunken gallery, other spaces were neglected as obelisk zone, therefore during the analysis procedures some places are more qualified to contain the LMD according to: 1) Pedestrians and users distributions; 2) Vehicles flow; 3) The variation of buildings height; 4) Places of services zone (parking, restaurants and kiosk).

To re-interacted the users within the spaces, the authors decided to divide the street into four zones with easy access for the pedestrians from the center and the other intermediate parties, therefore the circulations were defined by the intensity streets car flow, if the street flow are high as the southern side, the best way to access the space is form the parking to the center, otherwise if the cars flow is low as the northern, eastern and western side, the access are allowed from any point alongside.

Parallel to street flow and pedestrian distributed, the Height of Building (H.B.) was an important aspect to hold the LMD in wide range unlike the short facade, even the Empty Spaces (E.S.) was reuse as LMD holder to create a new interactive from inactive zone (obelisk), and we considered it as high interaction zone. The services are distributed in a way which served the zones, such as the parking, the restaurant and kiosk along the street which have a direct visual connection with the ambient, finally the position of the LMD's are variant through the street especially on (H.B.) facade and (E.S.) related to the interaction zone near surrounding services which emphasizing on the concept of mobility "slow-moving pedestrians require a high level of complexity to hold their interest” [6] (Figure 6 and Figure 7).

The results of the analysis show that; LMD embodied in the front area of the street continuously with diversity in the content for several reasons: to be distributed on the street to see what they interest about, and to not impede the traffic. Several Screens were placed sporadically in other areas that have a lack of cars flow and away from entrance, for ease of mobility along the street, taking into account the importance of smooth mobility around the service areas. In addition, the authors re-activate the nods in the street by adding digital elements leading to more interest zone. This embodied of Al-Thaqafa Street will transform the street to be more active, the LMD and its content will highlighted not only as a land mark, but also as an info mark or link mark [37]. 


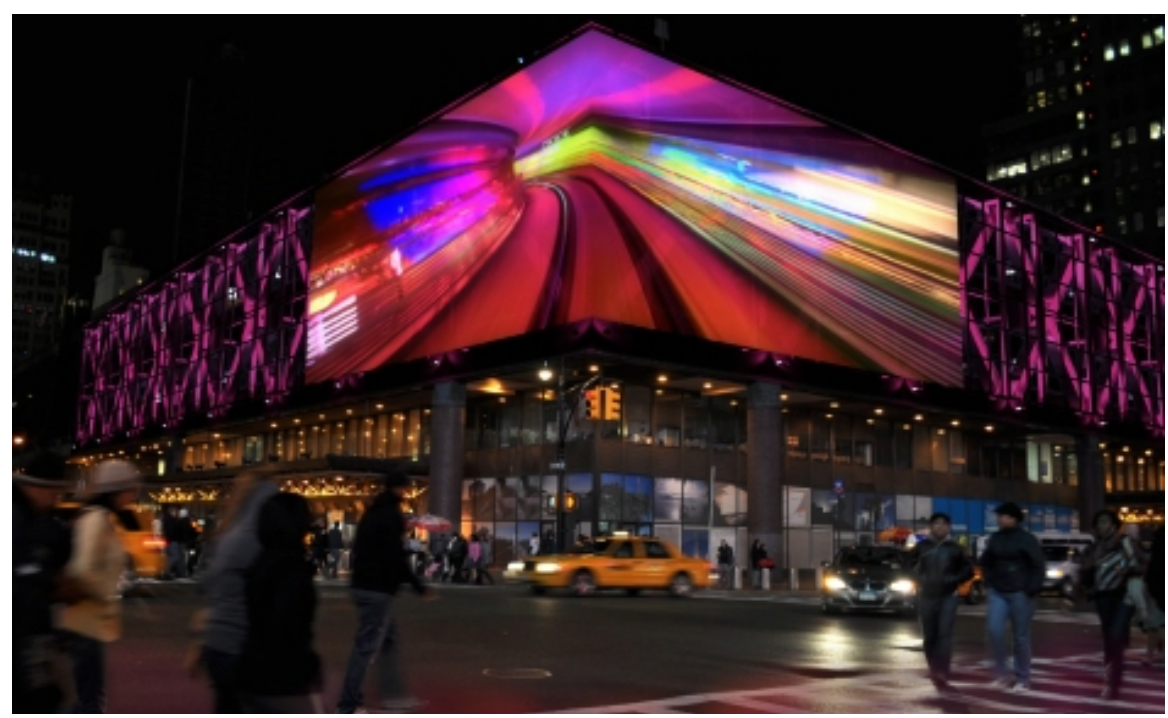

Figure 5. Authority bus terminal, LED media display, New York, United States (Alison, 2011).

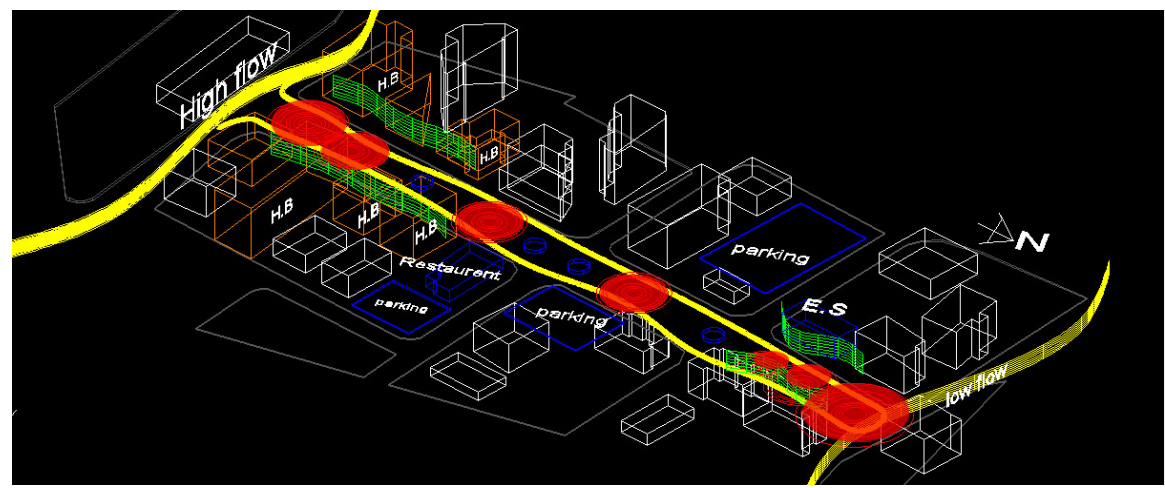

Figure 6. Showing the interest zone (red), car flow (yellow), L.M.D. (green), services (blue), high buildings-H.B. (orange).

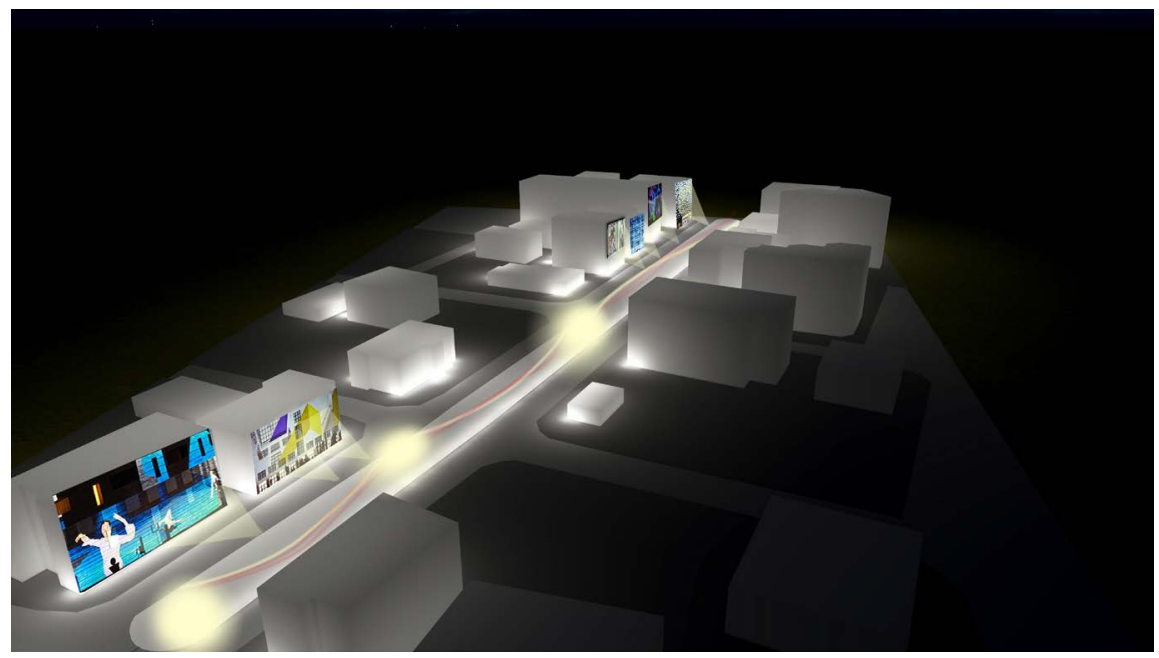

Figure 7. Showing the suggested position of the LMD, and the interactive zones within the street (highlight). The highlight lines show the users movements between LMD positions and interactive zones. 
Table 1. Showing the main nine questions in the questionnaire.

\begin{tabular}{lcc}
\hline \multicolumn{1}{c}{ Questions } & Yes & No \\
\hline Q1: Did you visit the street continuously? & $83 \%$ & $17 \%$ \\
Q2: Do you think that there is the importance of Al-Thaqafa? & $77 \%$ & $23 \%$ \\
Q3: Do you see that there is a link between the street name and its current status? & $10 \%$ & $90 \%$ \\
Q4: Do you think that Al-Thaqafa street is neglected and not activated? & $83 \%$ & $23 \%$ \\
Q5: Do you want to change the events contained within this space? & $73 \%$ & $17 \%$ \\
Q6: Do you think that Al-Thaqafa street building facades are important? & $97 \%$ & $3 \%$ \\
Q7: Do you think that the large media display will be interesting? & $97 \%$ & $3 \%$ \\
Q8: Do you think that large displays can change the quality of the street users and attract a greater & $100 \%$ & - \\
number of people? & \\
Q9: Do you think that the large media display will solve the problem of the street neglected? & Body movies \\
If your answer in Q7 is interest: What content do you prefer to display on the large media? & $40 \%$ \\
Touch-screen displays awareness games $\quad$ shows were created by the creators of street visitors & $40 \%$ \\
$23 \%$ & Natural séance \\
37\% & $63 \%$ & A variety of event such as sports \\
Short movies produced by local creators & $67 \%$
\end{tabular}

Table 2. Showing the following questions in the questionnaire.

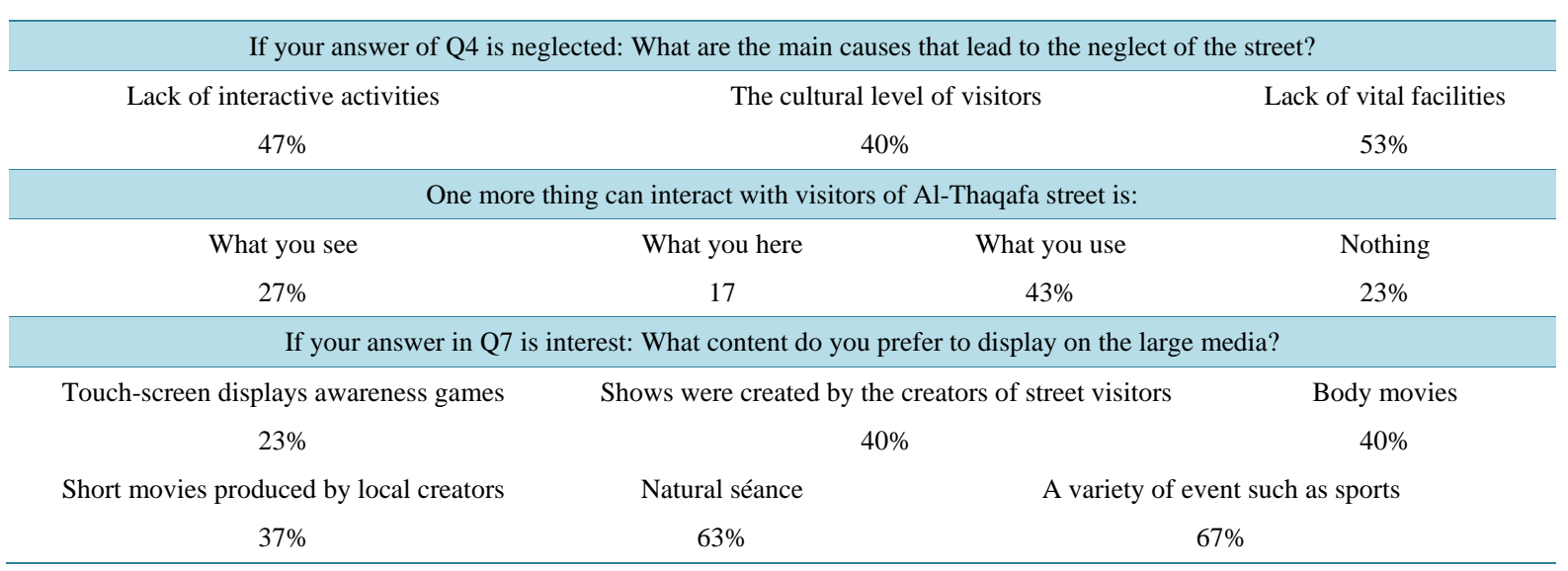

\section{Conclusion}

It appears that a new definition of urban spaces has rose during $21^{\text {st }}$ century, according to engaged and enhanced public spaces, in order to be more connectable to users. The paper tries to merge this neglected space, AlThaqafa Street, to its local society, and attempts to create a new cultural environment. By integrating the idea of interactive media on urban level, which previously studies, the paper gathered a response that supports this idea, leading to increase user's cognition to surrounding, by stimulating their opinions with a questionnaire that reforms the concept of the street. Therefore, the paper is an effort to redevelop parts of that space, by using the technology of LMD on the height of building's facade, in order to keep various distributions of users, with suggested topics to display also stimulated from the street users.

\section{References}

[1] Fischer, P. and Hornecker, E. (2012) Urban HCI: Spatial Aspects in the Design of Shared Encounters for Media Facades. CHI' 12 Proceedings of the SIGCHI Conference on Human Factors in Computing Systems, Austin, 5-10 May 2012, 307-316.

[2] Gehring, S. (2013) Media Facades: Turning Buildings into Large-Scale Interactive Surfaces. Proceedings of the Workshop on "Displays Take New Shape: An Agenda for Future Interactive Surfaces”, Paris, 27 April-2 May 2013, 12-16. 
[3] Meda, J. (2013) How Can Technology in Architecture Enhance the Experience of Cities. Bettery Magazine. http://betterymagazine.com/conversations/how-can-technology-in-architecture-enhance-the-experience-of-cities/

[4] Thiis-Evensen, T. (1987) Archetypes in Architecture. Oxford University Press, New York.

[5] Rapoport, A. and Kantor, R. (1967) Complexity and Ambiguity in Environmental Design. Journal of the Institute of American Planners, 33, 210-221. http://dx.doi.org/10.1080/01944366708977922

[6] Ewing, R. and Bartholomew, K. (2013) Pedestrian and Transit Oriented Design. Urban Land Institute and American Planning Association, Washington DC.

[7] Hillier, B. (2007) Space Is the Machine: A Configurational Theory of Architecture. Space Syntax, Electronic Edition, London.

[8] Hass-Klau, C. (1999) Streets as Living Space: Helping Public Spaces Play their Proper Role. Landor Publishing Limited, London.

[9] Woolley, H. and Rose, S. (2004) The Value of Public Space. The University Of Sheffield, London.

[10] Moggridge, B. (2007) Designing Interactions. The MIT Press, Cambridge.

[11] Diniz, N., Duarte, C. and Guimarães, N. (2012) Mapping Interaction onto Media Facades. Proceedings of the 2012 International Symposium on Pervasive Displays, Porto, 4-5 June 2012, 132-139. http://dx.doi.org/10.1145/2307798.2307812

[12] Williamson, D., et al. (2013) Low Resolution Displays for Performative Interaction in Public Spaces. EIPS, Workshop at CHI 2013, Paris, 28 April 2013, 44-47.

[13] Dalsgaard, P., Dindler, C. and Halskov, K. (2011) Understanding the Dynamics of Engaging Interaction in Public Spaces. In: Campos, P., et al., Ed., Human-Computer Interaction-INTERACT, Sage, Aarhus, 212-229.

[14] Stiles, R. (2013) A Guideline for Making Space, Part of the Project "Urban Space”. Central Europe Programme Co-Financed (ERDF), University of Technology, Vienna.

[15] Amin, M. (2002) Urban Quality and Designing of Spaces. International Planning Congress, Athens.

[16] Gehl, J. (2011) Life between Buildings: Using Public Spaces. 6th Edition, Island Press, London.

[17] Brignull, H. and Rogers, Y. (2003) Enticing People to Interact with Large Public Displays in Public Spaces. INTERACT'03 Proceedings: IFIP TC13 International Conference on Human-Computer Interaction, Zurich, 1-5 September 2003, 17-24.

[18] Saffer, D. (2010) Designing for Interaction: Creating Innovative Applications and Devices. 2nd Edition, New Riders, Berkeley.

[19] Harper, R., Rodden, T., Rogers, Y. and Sellen, A. (2008) Being Human: Human-Computer Interaction in the Year 2020 Experiencing Interactivity in Public Spaces. Microsoft Research Ltd., Cambridge.

[20] Dalsgaard, P. (2009) Designing Engaging Interactive Environments: A Pragmatist Perspective. PhD Thesis, Aarhus University, Aarhus.

[21] Kalčić, S. (2012) Architecture and New Media Art/Media Facade, Video and Lights-Installations. ICCMTD International Conference on Communication, Media, Technology and Design, Istanbul, 9-11 May 2012, 47-53.

[22] Vogel, D. and Balakrishnan, R. (2005) Interactive Public Ambient Displays. UIST '04, Proceedings of the 17th Annual ACM Symposium, ACM Digital Library, New York, 137-146.

[23] Jacobs, J. (1993) The Death and Life of Great American Cities. 4th Edition, Modern Library, New York.

[24] Binder, T., De Michelis, G., Gervautz, M., Jacucci, G., Matkovic, K., Psik, T. and Wagner, I. (2004) Supporting Configurability in a Mixed Media Environment for Design Students. Personal and Ubiquitous Computing, 8, 310-325. http://dx.doi.org/10.1007/s00779-004-0294-7

[25] Counsell, C. and Wolf, L. (2001) Performance Analysis: An Introductory Coursebook. Routledge, New York.

[26] Lefebvre, H. (2008) Space, Difference, Everyday Life. Routledge, New York.

[27] Michelis, D. and Müller, J. (2011) The Audience Funnel: Observations of Gesture-Based Interaction with Multiple Large Displays in a City Center. Anhalt University of Applied Science, Köthen.

[28] Kuikkaniemi, K., Jacucci, G., Turpeinen, M., Hoggan, E.E. and Müller, J. (2001) From Space to Stage: How Interactive Screens will Change Urban Life. The IEEE Computer Society, 1, 40-47.

[29] Lubis, B. and Primasari, A. (2012) The Relationship between People and Urban Screen in an Urban Space. ProcediaSocial and Behavioral Sciences, Elsevier, 42, 223-230.

[30] Lawson, B. (2001) The Language of Space. Architectural Press, London.

[31] Perovic, S. and Folic, N. (2012) Visual Perception of Public Open Spaces in Niksic. Procedia-Social and Behavioral 
Sciences, Elsevier, 68, 921-933.

[32] Botterweck, T. (2010) SPACING “Abstraction of Movement \& Dimension”. Electronic Edition. http://www.urbanscreen.com/usc/834

[33] Lozano-Hemmer, R. (2001) Body Movies, Relational Architecture No. 6-Installation in Public Space. Electronic Edition. http://www.absolutearts.com/artsnews/2001/08/31/29058.html

[34] Fritsch, J. and Brynsko, M. (2009) Between Engagement and Information: Experimental Urban Media in the Climate Change Debate. Workshop on Digital Cities 6, Penn State, 24 June 2009, 1-4.

[35] Alison, F. (2011) NYC Port Authority Bus Terminal: The World’s Largest Media Facade. ArchDaily, 14 July, Electronic Edition. http://www.archdaily.com/?p=148961

[36] Williams, A. (2003) How to ... Write and Analyse a Questionnaire. Journal of Orthodontics, 30, $245-252$. http://dx.doi.org/10.1093/ortho/30.3.245

[37] Fattahi, K. and Kobayashi, H. (2009) New Era, New Criteria for City Imaging. Theoretical and Empirical Researches in Urban Management, 3, 12-25. 
Scientific Research Publishing (SCIRP) is one of the largest Open Access journal publishers. It is currently publishing more than 200 open access, online, peer-reviewed journals covering a wide range of academic disciplines. SCIRP serves the worldwide academic communities and contributes to the progress and application of science with its publication.

Other selected journals from SCIRP are listed as below. Submit your manuscript to us via either submit@scirp.org or Online Submission Portal.
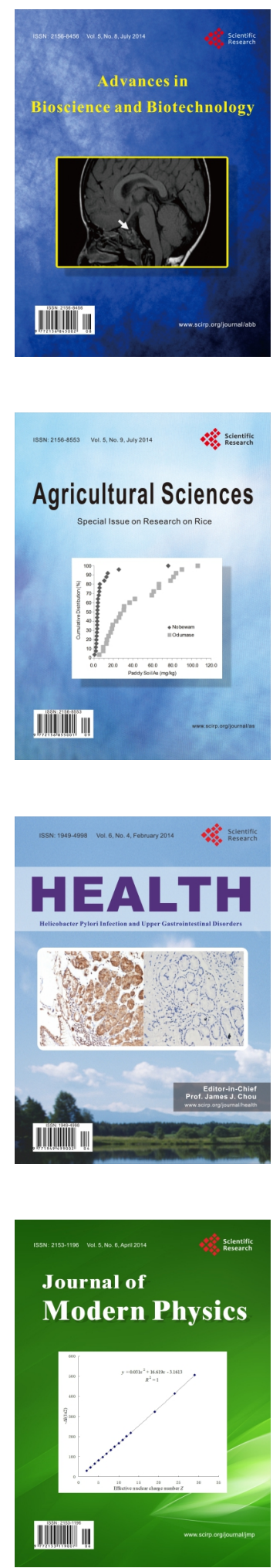
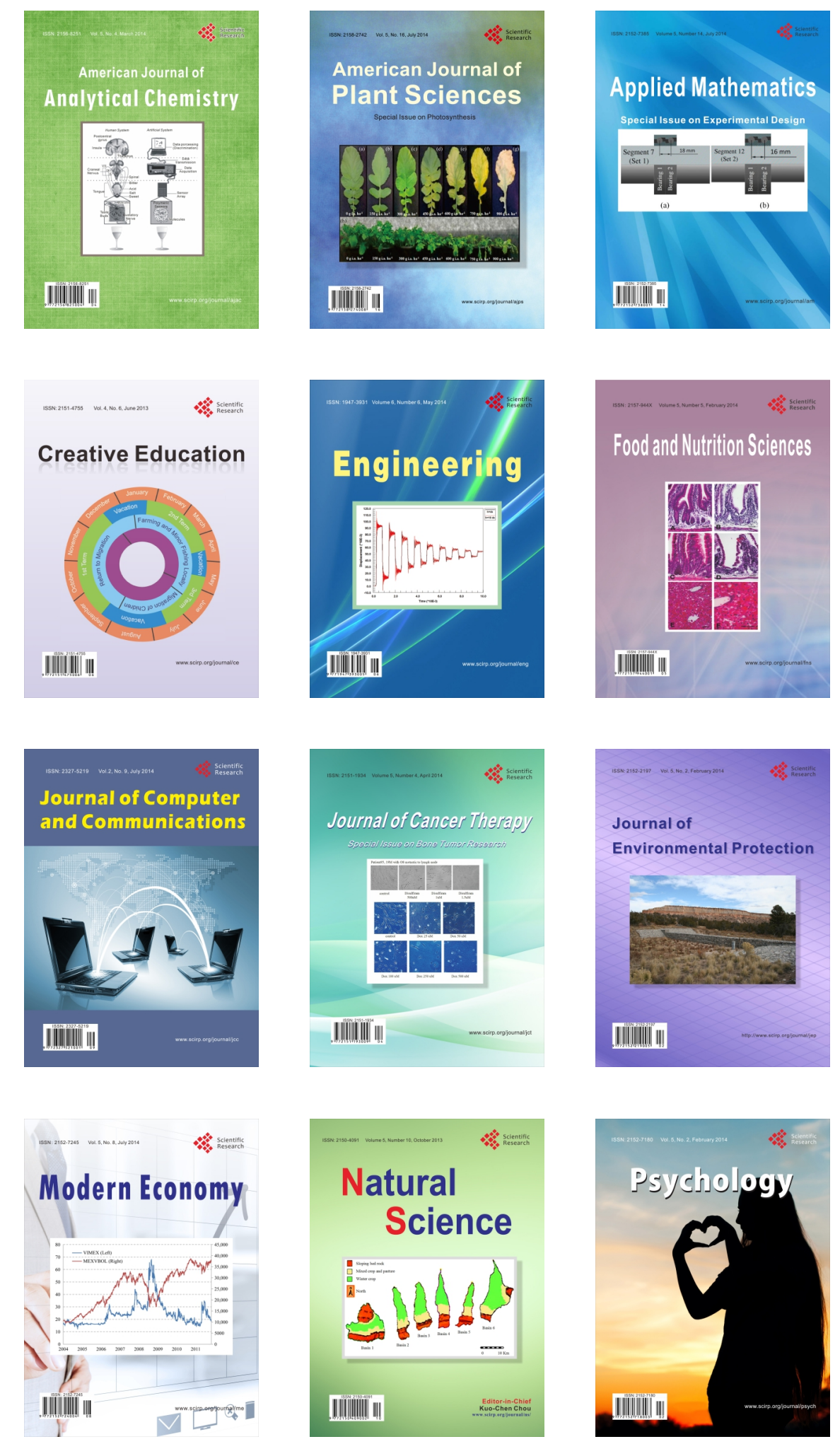